\title{
Differentiation of Hedyotis diffusa and Common Adulterants Based on Chloroplast Genome Sequencing and DNA Barcoding Markers
}

\author{
Mavis Hong-Yu Yik ${ }^{1,+(1)}$, Bobby Lim-Ho Kong ${ }^{1,2,+}$, Tin-Yan Siu ${ }^{2}$, David Tai-Wai Lau ${ }^{1,2}$, Hui Cao $^{3}$ \\ and Pang-Chui Shaw 1,2,4,* \\ 1 Li Dak Sum Yip Yio Chin R \& D Center for Chinese Medicine, The Chinese University of Hong \\ Kong, Shatin, N.T., Hong Kong, China; mavisyik@cuhk.edu.hk (M.H.-Y.Y.); \\ 1155047596@link.cuhk.edu.hk (B.L.-H.K.); lautaiwai@cuhk.edu.hk (D.T.-W.L.) \\ 2 Shiu-Ying Hu Herbarium, School of Life Sciences, The Chinese University of Hong Kong, Shatin, N.T., \\ Hong Kong, China; joycesiu@cuhk.edu.hk \\ 3 Research Center for Traditional Chinese Medicine of Lingnan (Southern China) and College of Pharmacy, \\ Jinan University, Guangzhou 510632, China; kovhuicao@aliyun.com \\ 4 State Key Laboratory of Research on Bioactivities and Clinical Applications of Medicinal Plants (CUHK), \\ The Chinese University of Hong Kong, Shatin, N.T., Hong Kong, China \\ * Correspondence: pcshaw@cuhk.edu.hk; Tel.: +852-39431363; Fax: +852-26037246 \\ + The authors contributed equally.
}

check for updates

Citation: Yik, M.H.-Y.; Kong, B.L.-H.; Siu, T.-Y.; Lau, D.T.-W.; Cao, H.; Shaw, P.-C. Differentiation of Hedyotis diffusa and Common Adulterants Based on Chloroplast Genome Sequencing and DNA Barcoding Markers. Plants 2021, 10, 161 https://doi.org/doi:10.3390 /plants10010161

Received: 15 December 2020

Accepted: 13 January 2021

Published: 15 January 2021

Publisher's Note: MDPI stays neutral with regard to jurisdictional claims in published maps and institutional affiliations.

Copyright: (c) 2021 by the authors. Licensee MDPI, Basel, Switzerland. This article is an open access article distributed under the terms and conditions of the Creative Commons Attribution (CC BY) license (https:/ / creativecommons.org/licenses/by/ $4.0 /)$.

\begin{abstract}
Chinese herbal tea, also known as Liang Cha or cooling beverage, is popular in South China. It is regarded as a quick-fix remedy to relieve minor health problems. Hedyotis diffusa Willd. (colloquially Baihuasheshecao) is a common ingredient of cooling beverages. H. diffusa is also used to treat cancer and bacterial infections. Owing to the high demand for H. diffusa, two common adulterants, Hedyotis brachypoda (DC.) Sivar and Biju (colloquially Nidingjingcao) and Hedyotis corymbosa (L.) Lam. (colloquially Shuixiancao), are commonly encountered in the market. Owing to the close similarity of their morphological characteristics, it is difficult to differentiate them. Here, we sequenced the complete chloroplast genomes of the three species of Hedyotis using next-generation sequencing (NGS). By comparing the complete chloroplast genomes, we found that they are closely related in the subfamily Rubioideae. We also discovered that there are significant differences in the number and repeating motifs of microsatellites and complex repeats and revealed three divergent hotspots, rps16-trn $Q$ intergenic spacer, $n d h D$ and $y c f 1$. By using these species-specific sequences, we propose new DNA barcoding markers for the authentication of $H$. diffusa and its two common adulterants.
\end{abstract}

Keywords: Hedyotis; chloroplast genome; herbal medicine; authentication; DNA barcode; ndhD; ycf1; rps16-trnQ

\section{Introduction}

Chinese herbal tea, also known as Liang Cha or cooling beverage, is a decoction of multiple herbs popular in South China and tropical Asia [1]. It is used to treat minor illnesses, including flu symptoms. Owing to its popularity, herbal tea was inscribed into the first National List of Intangible Cultural Heritage in 2006 by the State Council of the People's Republic of China.

Species of Hedyotis, a genus of approximately 500 species in the family Rubiaceae [2], are annual or perennial herbs that are mainly distributed in tropical and subtropical regions [3]. Many species of Hedyotis, for example, H. biflora [4], H. herbacea [5] and $H$. chrysotricha [6], are used as folk medicine or as ingredients in herbal products for health maintenance. $H$. diffusa is a well-known ingredient in cooling beverages, which are consumed daily to quench thirst and to modulate the immune system [7], to prevent inflammatory diseases and to maintain good health. H. diffusa also possesses the pharmacological 
effects of anti-oxidation, anti-tumor and anti-inflammatory properties for treating different kinds of cancers, such as colorectal cancer, leukemia and multiple myeloma [8-10].

The surging demand for $H$. diffusa has resulted in the emergence of two common adulterants, H. brachypoda (DC.) Sivar and Biju (colloquially Nidingjingcao) and H. corymbosa (L.) Lam. (colloquially Shuixiancao) in the market. Although the morphological characteristics of these three species are only slightly different, they have distinct phytochemicals, for example, Hedyotiscone A is found only in H. corymbosa [11] and, 6-O-(E)-p-coumaroyl scandoside methyl ester and 10(S)-hydroxypheophytin only in $H$. diffusa [12]. There have been studies on the authentication of $H$. diffusa using distinctive chemical markers. However, the use of chloroplast genomes for comparing this species with its common adulterants have not been available. To further enhance the quality assurance and quality control of Hedytois species in the herbal industry, we set forth to sequence the complete chloroplast genomes of these three species of Hedyotis. Besides analyzing their genome organization and features for understanding their phylogenetic relationship, we also found DNA barcoding markers for authenticating them effectively.

\section{Results}

\subsection{Chloroplast Genome Organization}

For the three species of Hedyotis, paired-end reads with $150 \mathrm{bp}$ in average length were generated by Illumina sequencing. In Genbank, the only available Hedyotis chloroplast genome is Hedyotis ovata (MK203877). It was used as reference for mapping reads. The sizes of chloroplast genomes of $H$. diffusa, $H$. brachypoda and $H$. corymbosa were 153,653, 153,617 and 152,327 bp, respectively (Figure 1, Table 1). They had a typical quadripartite structure including one large single-copy region (LSC) (83,609 to 83,863 bp), one small single-copy region (SSC) (17,195 to 18,146 bp), and a pair of inverted repeat regions (IRa and IRb) $(25,286$ to $26,321 \mathrm{bp})$. The GC contents among the three species were similar with a value around $37 \%$.

Apart from the basic characteristics of the three chloroplast genomes, the genes in the chloroplast genomes were analyzed. The total number of genes encoded in $H$. diffusa, $H$. brachypoda and H. corymbosa was 130, 129 and 128, respectively. The encoded genes were classified into four functional categories: protein synthesis and DNA-replication, photosynthesis, miscellaneous group and unknown functions. Genes were classified into different gene groups of the categories (Table 2). The genes containing introns and pseudogenes were analyzed. In addition, there were 19 genes located within the IR regions and therefore were duplicated in the genome.

Table 1. The basic characteristics of the chloroplast genomes of the three Hedyotis species.

\begin{tabular}{cccc}
\hline Characteristics & $\begin{array}{c}\text { Hedyotis diffusa } \\
\text { (MT767008) }\end{array}$ & $\begin{array}{c}\text { Hedyotis brachypoda } \\
\text { (MT767007) }\end{array}$ & $\begin{array}{c}\text { Hedyotis corymbosa } \\
\text { (MT767006) }\end{array}$ \\
\hline Specimen Voucher & $\mathrm{H} 2200$ & $\mathrm{H} 2174$ & $\mathrm{H} 2106$ \\
Total Size (bp) & 153,653 & 153,617 & 152,327 \\
Large Single Copy (LSC, bp) & 83,863 & 83,780 & 83,609 \\
Small Single Copy (SSC, bp) & 17,218 & 17,195 & 18,146 \\
Inverted Repeat (IR, bp) & 26,286 & 26,321 & 25,286 \\
Total number of genes & 130 & 129 & 128 \\
Protein-coding genes & 85 & 84 & 83 \\
tRNA genes & 37 & 37 & 37 \\
rRNA genes & 8 & 8 & 8 \\
GC content (\%) & 37.62 & 37.61 & 37.41 \\
\hline
\end{tabular}


a
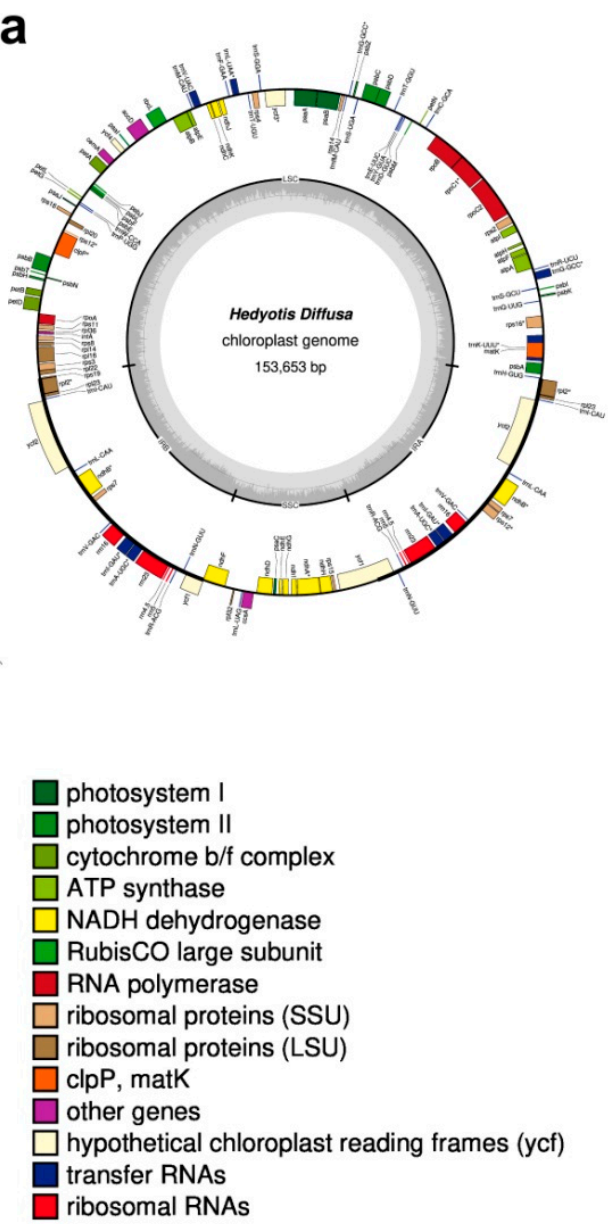

b

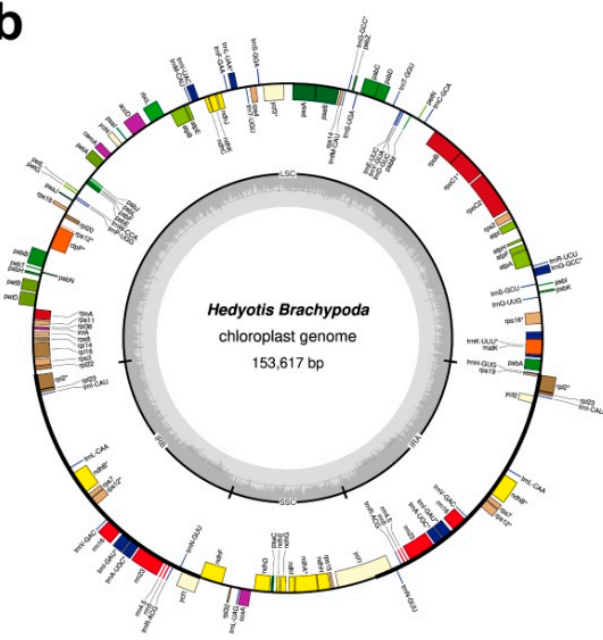

C

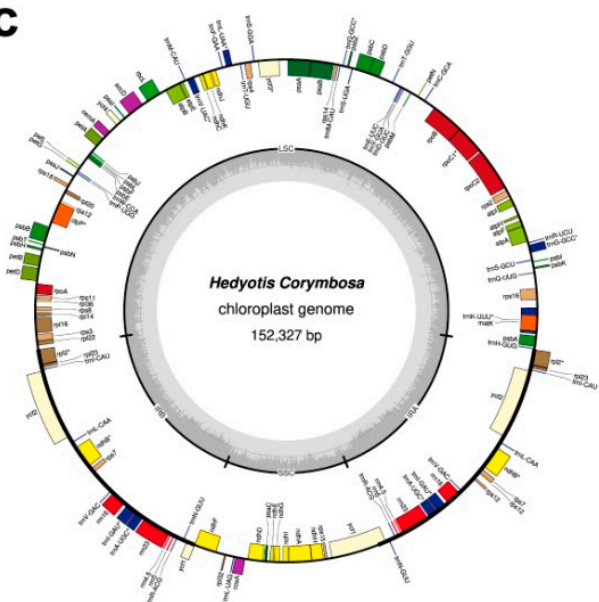

Figure 1. Gene maps of the chloroplast genomes of the three Hedyotis species. (a) Hedyotis diffusa; (b) Hedyotis brachypoda; (c) Hedyotis corymbosa. The genes shown inside and outside of the circles are transcribed clockwise and counterclockwise, respectively. Genes belonging to different functional groups are color-coded. The darker gray area and the lighter gray area in the inner circle represent the GC and AT content of the chloroplast genome.

Table 2. List of genes in the chloroplast genomes of the three Hedyotis species.

\begin{tabular}{|c|c|c|}
\hline Category & Gene Group & Gene Name \\
\hline \multirow{12}{*}{ Protein synthesis and DNA-replication } & Ribosomal RNA genes & rrn4.5, rrn5, rrn16, rrn23 \\
\hline & & trnH-GUG, trnL-UAG, trnQ-UUG, \\
\hline & & $\operatorname{trnS}-G C U, \operatorname{trnR}-U C U, \operatorname{trn} \widetilde{C}-G C A$ \\
\hline & & trnD-GUC, trnY-GUA, trnE-UUC, \\
\hline & & trnT-GGU, trnS-UGA, trnfM-CAU, \\
\hline & Transfer RNA genes & trnS-GGA, trnT-UGU, trnF-GAA, \\
\hline & & $\begin{array}{l}\operatorname{trnM}-C A U, \operatorname{trnW}-C C A, \operatorname{trn} P-U G G, \\
\text { trnV-UAC trnL-UAA * trnK-UUU * }\end{array}$ \\
\hline & & trnG-GCC *, trnI-CAU, trnL-CAA, \\
\hline & & $\begin{array}{c}\operatorname{trn} V-G A C, \operatorname{trnI}-G A U^{*}, \operatorname{trn} A-U G C^{*}, \\
\operatorname{trnR}-A C G, t r n N-G U U\end{array}$ \\
\hline & Small subunit of ribosome & $\begin{array}{l}r p s 2, r p s 3, r p s 4, r p s 7, r p s 8, r p s 11, r p s 12 * \\
r p s 14, r p s 15, r p s 16^{*}, r p s 18, r p s 19^{\delta}\end{array}$ \\
\hline & Large subunit of ribosome & $\begin{array}{c}r p l 2 *, r p l 14, r p l 16, r p l 20, r p l 22, r p l 23 \\
r p l 32, r p l 36\end{array}$ \\
\hline & RNA polymerase subunits & $r p o A, r p o B, r p o C 1 *, r p o C 2$ \\
\hline
\end{tabular}


Table 2. Cont.

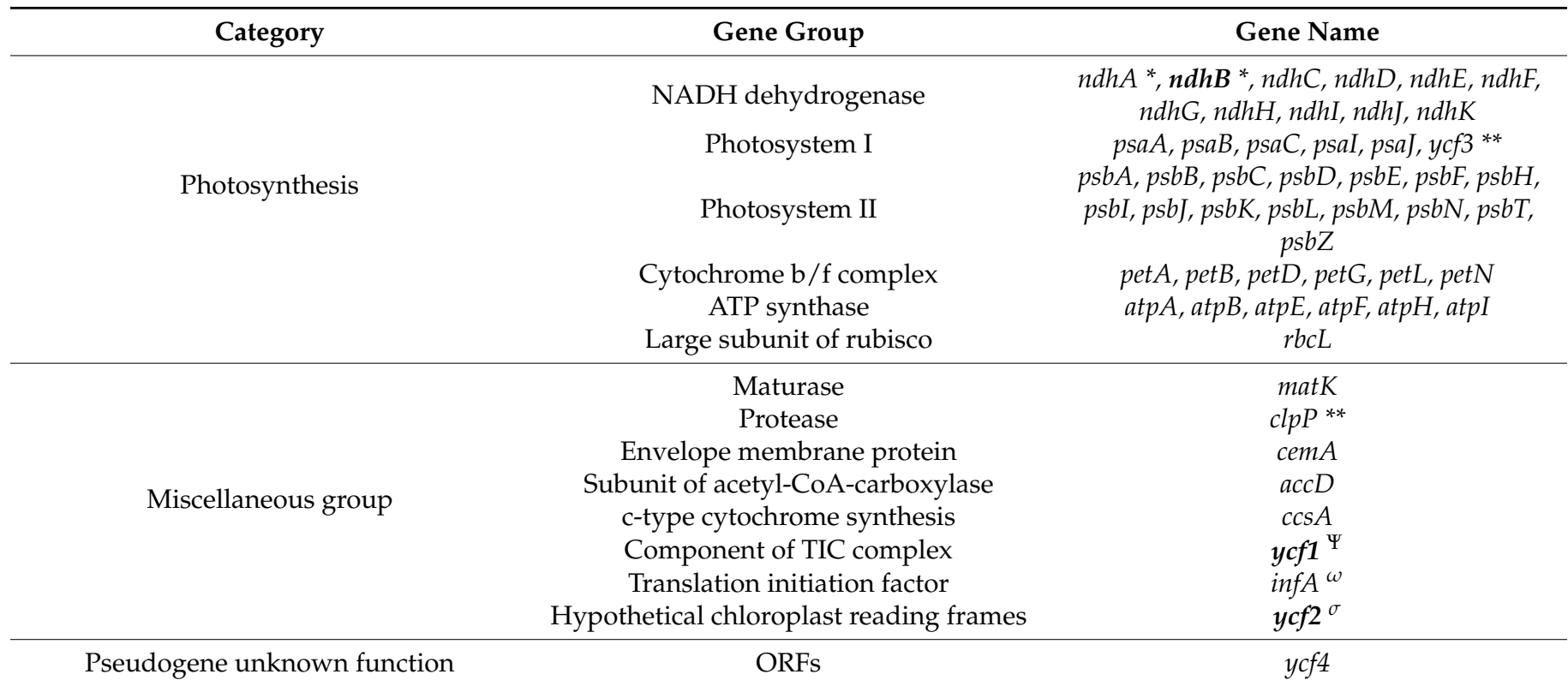

${ }^{*}$ Genes containing one introns; ${ }^{* *}$ Genes containing two introns; ${ }^{\Psi}$ Pseudogene in H. diffusa, H. brachypoda and H. corymbosa ${ }^{\delta}$ Pseudogene in H. brachypoda and H. corymbosa only; ${ }^{\sigma}$ Pseudogene in H. brachypoda only; ${ }^{\omega}$ Pseudogene in H. corymbosa only; Genes in bold are located within the IR and therefore are duplicated.

\subsection{Analysis of Repeat Sequences}

There are variations among the three species of Hedyotis in the number of simple sequence repeats and dispersed repeats. The number of simple sequence repeats (SSRs) in $H$. diffusa, $H$. brachypoda and $H$. corymbosa was 47,42 and 48 respectively. The number of mono-, di-, tri-, tetra-, penta-, and hexa-nucleotides were analyzed (Figure 2). Mono-nucleotide repeats were the most abundant. They accounted for over $50 \%$ of the total SSRs, while hexa-nucleotides were the rarest, with only one repeat in $H$. diffusa but none in the others.

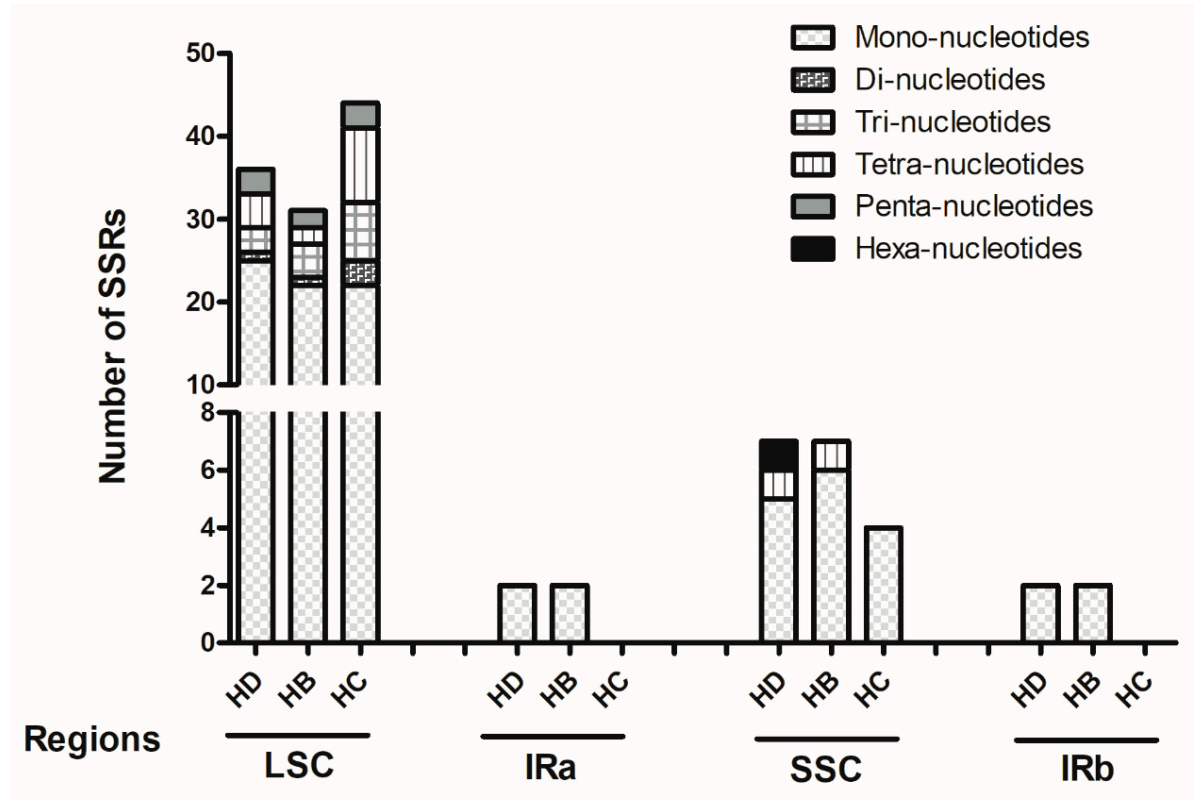

Figure 2. Analysis of simple sequence repeats (SSRs) in the six categories of SSRs in four different regions of the chloroplast genomes. HD: H. diffusa, HB: H. brachypoda, HC: H. corymbosa. 
The number of dispersed repeats in H. diffusa, H. brachypoda and H. corymbosa was 19, 20 and 22 respectively. Forward match, reverse match, complement match and palindromic match with repeat length ranging from 21 to $70 \mathrm{bp}$ were analyzed (Figure 3). Most occurring repeats were palindromic matches, followed by forward match, reverse match and complement match.

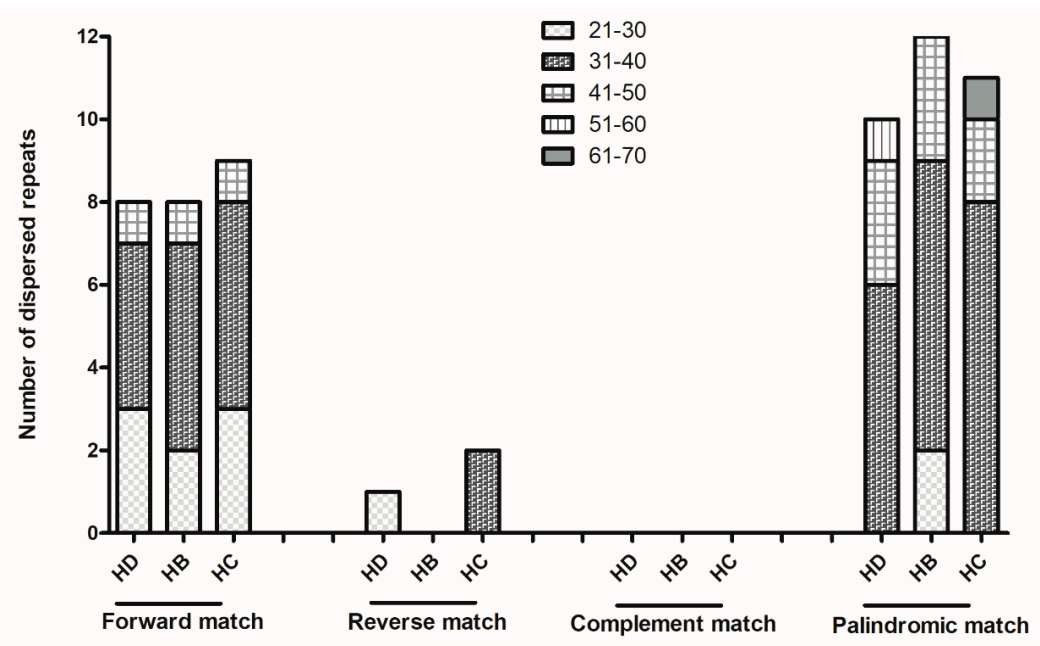

Figure 3. Analysis of four kinds of complex sequence repeats in the three chloroplast genomes. HD: H. diffusa, HB: H. brachypoda, HC: H. corymbosa.

\subsection{Genome Sequence Divergence Analysis}

Nucleotide diversity in the chloroplast genome and highly variable regions can be revealed through sliding window analysis [13]. Comparing the three species of Hedyotis, the nucleotide diversity values $(\mathrm{Pi})$ ranged from 0 to 0.095 , with an average value of 0.00246 . Obviously, sequence divergence was concentrated in the LSC and SSC regions, but showed less variability in the IR regions (Figure 4). Three divergent hotspots rps16-trnQ intergenic spacer, $n d h D$ and $y c f 1$, with distinctive high Pi values of $0.095,0.089$ and 0.083 respectively were revealed. The rps16-trnQ intergenic spacer is located in the LSC region, while $n d h D$ and $y c f 1$ are in the SSC and IRb regions respectively.

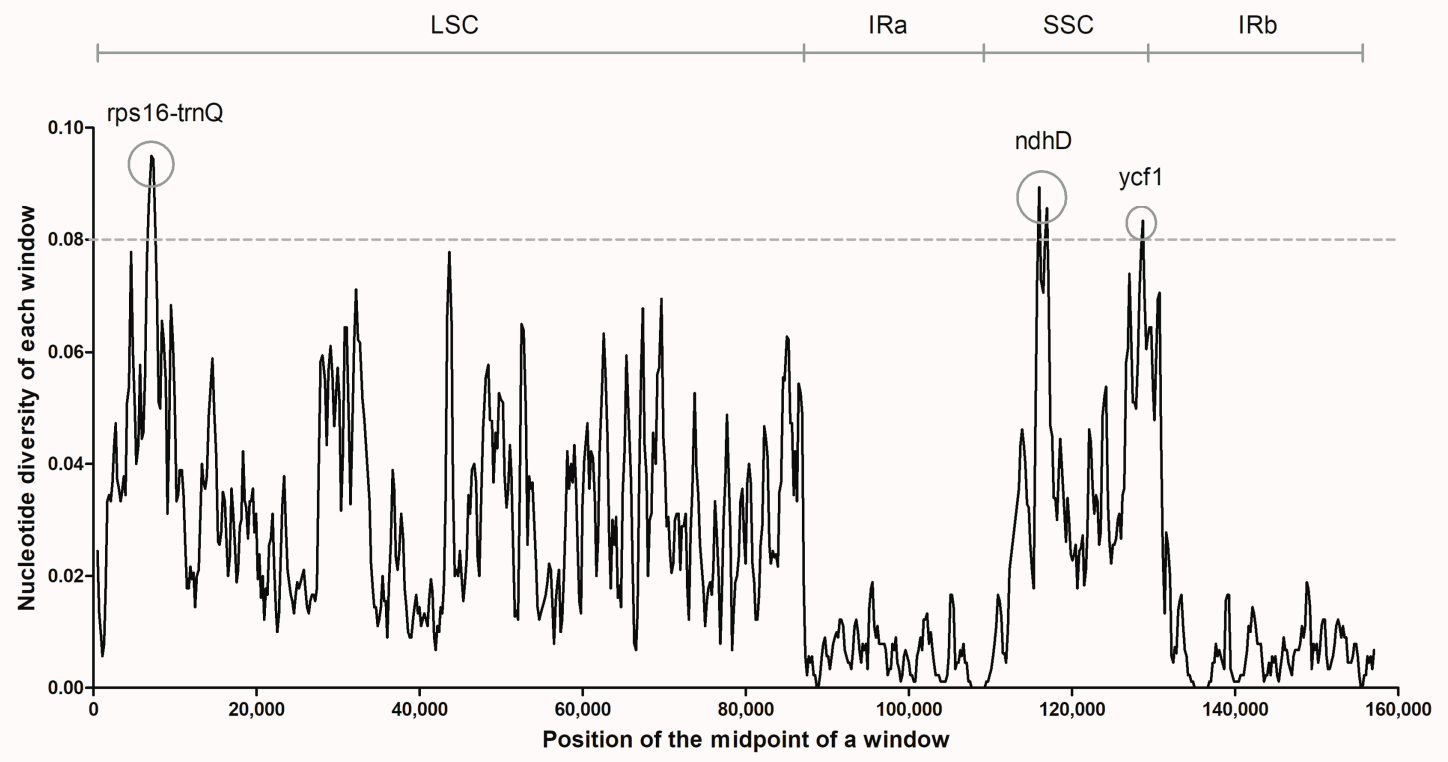

Figure 4. Sliding window analysis of the three chloroplast genomes. Analytic parameters: 600 bp of window length and 200 bp of step size. $X$-axis: Midpoint of a window; $Y$-axis: Nucleotide diversity of each window (Pi). 
Insertions/deletions (indels) and single nucleotide polymorphism (SNPs) were also considered (Table 3) for further analyzing the genome sequence divergence. Using the $H$. diffusa chloroplast genome as reference, indels and SNP of the other two chloroplast genomes were compared. The number of SNP and indels of $H$. corymbosa were around 4 and 3 times higher than in $H$. brachypoda when compared to $H$. diffusa, indicating that the genomic difference of $H$. corymbosa is much greater than $H$. brachypoda when compared with $H$. diffusa.

Table 3. Comparison of insertions/deletions (indels) and single nucleotide polymorphisms (SNPs) of the three Hedyotis species. The upper and lower triangles show the number of SNPs and indels in the complete chloroplast genomes respectively.

\begin{tabular}{cccc}
\hline & Hedyotis diffusa & Hedyotis brachypoda & Hedyotis corymbosa \\
\hline Hedyotis diffusa & & 1051 & 4996 \\
Hedyotis brachypoda & 198 & & 5061 \\
Hedyotis corymbosa & 684 & 677 & \\
\hline
\end{tabular}

\subsection{Phylogenetic Analysis}

The phylogenetic relationship among plant lineages can be elucidated through the analysis of chloroplast genome sequences [14,15]. Figure 5 shows the phylogenetic relationship of the four species of Hedyotis and other species of Rubiaceae. The tree revealed that $H$. diffusa is closer to H. brachypoda than H. corymbosa. Nevertheless, they all belong in the subfamily of Rubioideae. The phylogenetic tree was highly supported with bootstrap values of 100 .
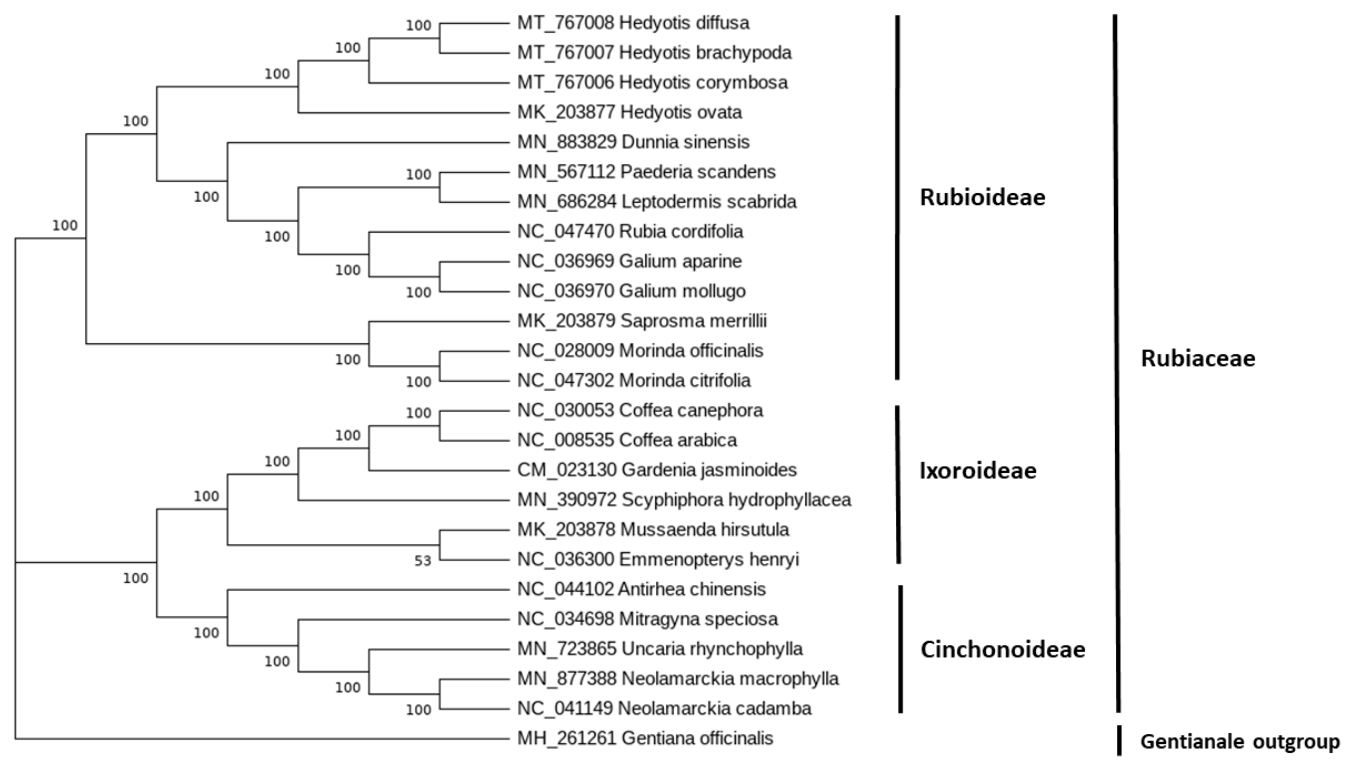

Figure 5. Phylogenetic relationships of the four Hedyotis species and other species of Rubiaceae with available complete chloroplast genome sequences using maximum likelihood (ML).

\subsection{Development of DNA Barcoding Markers}

Owing to the short amplicon size and the presence of common region in the $n d h D$ and $r p s 16-t r n Q$ intergenic spacer among the three Hedyotis species, primers were designed for species identification. The ycf1 region was not chosen as the barcoding region as it is too long and too variable to permit the design of universal primers. This phenomenon for ycf1 has also been found in Nicotiana tabacum [16]. PCR was first performed by using the designed primers on the ten samples. Amplicons were then sequenced, and DNA sequences were aligned with the corresponding regions in the chloroplast genomes we have obtained. Ten samples of Hedyotis species were obtained from the market for molecular 
authentication. Their identities were also identified by morphological characterization. Both approaches give consistent authentication results (Table 4). Sequences of the primers and the amplicons are shown in Tables S1 and S2.

Table 4. Molecular authentication of Hedyotis samples from the market.

\begin{tabular}{|c|c|c|c|c|c|c|c|}
\hline \multirow{2}{*}{$\begin{array}{l}\text { Specimen } \\
\text { Voucher }\end{array}$} & \multicolumn{3}{|c|}{$\begin{array}{l}\text { Percentage Identity with } n d h D \text { in } \\
\text { Chloroplast Genome }\end{array}$} & \multicolumn{3}{|c|}{$\begin{array}{l}\text { Percentage Identity with } r p s 16-t r n Q \text { in } \\
\text { Chloroplast Genome }\end{array}$} & \multirow{2}{*}{$\begin{array}{l}\text { Sample } \\
\text { Identity }\end{array}$} \\
\hline & $\begin{array}{c}H . \\
\text { corymbosa }\end{array}$ & $\begin{array}{c}H . \\
\text { brachypoda }\end{array}$ & H. diffusa & $\begin{array}{c}H . \\
\text { corymbosa }\end{array}$ & $\begin{array}{c}H . \\
\text { brachypoda }\end{array}$ & H. diffusa & \\
\hline T5084 & $100 \%$ & $97 \%$ & $97 \%$ & $99 \%$ & $85 \%$ & $85 \%$ & H. corymbosa \\
\hline T5089 & $97 \%$ & $100 \%$ & $99 \%$ & $86 \%$ & $97 \%$ & $96 \%$ & H. brachypoda \\
\hline T5093 & $100 \%$ & $97 \%$ & $97 \%$ & $99 \%$ & $87 \%$ & $86 \%$ & H. corymbosa \\
\hline T5097 & $100 \%$ & $97 \%$ & $97 \%$ & $99 \%$ & $87 \%$ & $87 \%$ & H. corymbosa \\
\hline T5101 & $97 \%$ & $100 \%$ & $99 \%$ & $87 \%$ & $98 \%$ & $97 \%$ & H. brachypoda \\
\hline T5106 & $100 \%$ & $97 \%$ & $97 \%$ & $100 \%$ & $87 \%$ & $87 \%$ & H. corymbosa \\
\hline T5110 & $97 \%$ & $100 \%$ & $99 \%$ & $87 \%$ & $98 \%$ & $97 \%$ & H. brachypoda \\
\hline T5114 & $97 \%$ & $100 \%$ & $99 \%$ & $87 \%$ & $98 \%$ & $97 \%$ & H. brachypoda \\
\hline T5121 & $97 \%$ & $100 \%$ & $99 \%$ & $87 \%$ & $98 \%$ & $97 \%$ & H. brachypoda \\
\hline T5126 & $97 \%$ & $100 \%$ & $99 \%$ & $87 \%$ & $98 \%$ & $97 \%$ & H. brachypoda \\
\hline
\end{tabular}

\section{Discussion}

\subsection{Chloroplast Genome Features}

Chloroplasts are vital cell organelles in plants, playing an important role in energy production in photosynthesis and in plant growth and development $[17,18]$. Same as nucleus and mitochondria, chloroplast has its own genetic material. The basal genomic information helps in addressing phylogenetic and authentication problems [19].

Among the three Hedyotis species, the number of protein-coding genes differed, while the number of tRNA and rRNA genes, gene order and clusters were conserved, perhaps due to long-term evolution under environmental pressures, similar to the case of Robinia [20]. Genomic differences also derived from the presence of different pseudogenes. ycf1 is a common one, and its presence may be due to the incomplete duplication of the normal copy between the SSC and IRb regions [21]. There are three other pseudogenes, rps19 and ycf2 in H. brachypoda and rps19 and infA in H. corymbosa. Their existence is due to the occurrence of internal stop codons and results in a massive deletion. These pseudogenes have also been found in other plants, for example, ycf2 in maize [22], infA in Oenothera elata [23] and rps19 in Malpighiaceae [24]. In addition, the start codon of the $n d h D$ gene, which functions in photosynthesis, had been altered from the common initiation codon AUG to ACG. This may be due to a post transcriptional RNA editing process that induced substitution or indel mutation [25]. The C-to-U RNA editing in plant chloroplasts is common in flowering plants [26].

Repeat sequences contribute to genomic rearrangement, recombination, and sequence divergence [27]. In this study, H. corymbosa had the largest number of repeats (70), including both simple sequence repeats and dispersed repeats, while $H$. brachypoda had the fewest (62). The analysis indicated that the genetic variation and diversity may mainly be due to (1) simple sequence repeats-mainly mono-nucleotides, but also hexa-nucleotides-and (2) dispersed repeats: palindromic match with 31-40 repeat lengths. Moreover, over $70 \%$ of the simple repeats were located in the LSC region, followed by the SSC region and the IR region, suggesting that the IR regions are less variable than the other two regions [28].

\subsection{Sequence Divergence, Phylogenetic Relationships and Molecular Markers for Authentication}

The sequence divergence was clearly indicated by the sliding window and indels/SNPs analysis. The nucleotide diversity in IR regions is low, with Pi values less than 0.02 , which means less genetic variation among the three species of Hedyotis in the IR regions. 
This phenomenon was consistent with findings in other chloroplast genome studies [29,30], which suggests the low sequence variation in IR regions was by virtue of gene conversion for copy correction of IR sequences [31]. The three hotspot regions discovered with Pi values higher than 0.08 have potential to develop DNA barcoding markers [16]. Moreover, the indels/SNPs results revealed that the genomic difference of $H$. corymbosa is much higher than $H$. brachypoda when compared with $H$. diffusa. This showed a consistent conclusion with the phylogenetic relationship of the three species of Hedyotis.

With the genetic variation discovered, we analyzed the phylogenetic relationship of the four species of Hedyotis and other species of Rubiaceae using complete chloroplast genomes for the determination of their phylogenetic relationship. From the phylogenetic analysis, all the Rubiaceae species were basically divided into two branches. One branch consisted of species in the subfamily of Rubioideae, while another consisted of species in subfamilies of Ixoroideae and Cinchonoideae. All four species of Hedyotis belonged to the subfamily of Rubioideae. The analytical result revealed that $H$. diffusa and $H$. brachypoda are closer to each other with the same branching point; however, they are less close to $H$. corymbosa as well as $H$. ovata. The phylogenetic analysis is consistent with the classification of Flora Republicae Popularis Sinicae. Both the H. diffusa and H. corymbosa belong to the section Euoldenlandia, while H. ovata belongs to section Diplophragma. According to Flora of China, H. brachypoda is commonly circumscribed as H. diffusa, although the taxonomy of these two species is unsolved. As expected, $H$. diffusa and $H$. brachypoda had a closer relationship in our phylogenetic analysis. H. ovata was also successfully classified into a different lineage with the other three Hedyotis species.

Recently, the use of whole chloroplast genomes in developing specific barcodes for distinguishing closely related plant species has been proposed [32,33]. DNA barcoding is a widely used tool for species identification and authentication [34]. It has also been used to identify material present in processed seafood products for promoting food safety [35]. In this study, we designed primers with amplicon size 200-300 bp from the two identified hotspot regions $n d h D$ and rps16-trnQ intergenic spacer. DNA from dried herbs are always degraded during manufacturing processes [36]. The proposed specific barcodes are superior to universal barcodes because (1) the specific primers are designed from hotspot regions with great variations among target species, which is good for identification, and (2) the amplicons are small enough, which is more appropriate for processed herbal products. With the specific barcodes, the quality control of Hedyotis-containing herbal beverages can be enhanced.

\section{Materials and Methods}

\subsection{Collection of Plant Samples}

Fresh plants of $H$. diffusa, $H$. brachypoda and $H$. corymbosa were collected at various locations in the Chinese University of Hong Kong. The samples with voucher specimens were deposited in the Shiu-Ying Hu Herbarium, Chinese University of Hong Kong. The specimens were collected based on the delimitation of the three species according to the treatment of Sivarajan and Biju [37]. The identification of H. diffusa was based on the taxonomic treatment characterizing species with 3 to 7 flowered cymes or 1 to 2 flowered cymes and without a ring of hairs in the corolla. H. brachypoda was characterized as being 1 to 2 flowered and lacking a ring of hairs in the corolla. H. corymbosa was characterized by having 3 to 8 flowered cymes or rarely with solitary flower, and with a ring of hairs in the corolla.

\subsection{DNA Extraction}

For DNA extraction, $200 \mathrm{mg}$ of fresh plant samples were ground by liquid nitrogen for DNA extraction using DNeasy plant mini kit (Qiagen, Germany), and $400 \mu \mathrm{L}$ AP1 extraction buffer, $4 \%$ Polyvinylpyrrolidone (PVPP), $2 \% \beta$-mercaptoethanol and $4 \mu \mathrm{L}$ RNase A $(100 \mathrm{mg} / \mathrm{mL})$ were added to the samples and incubated at $65^{\circ} \mathrm{C}$ for $10 \mathrm{~min}$. The protocol 
of the manufacturer was then followed. Fifty microliters elution buffer was used to collect the purified DNA.

\subsection{Chloroplast Genome Sequencing, Assembling and Annotation}

The three samples of extracted genomic DNA were sequenced by Novogene Corporation Inc., China. Libraries were generated using NEBNext DNA Library Prep Kit (NEB, Ipswich, MA, USA) and sequenced using the Illumina NovaSeq 6000 platform (Illumina, USA). The number of pair-end reads of $H$. diffusa, $H$. brachypoda and $H$. corymbosa were $169,465,174,248$ and 169,635 respectively, with $150 \mathrm{bp}$ read length. The raw data were trimmed and assembled into contigs using CLC assembly cell v4.21.104315 and SOAPdenovo v. 3.23, with default parameters set. Gapcloser module in SOAP package was used for gap filling. A reference genome of H. ovata (MK203877) was downloaded for contigs alignment and chloroplast genome assembly. All paired-end reads were mapped to the assembled chloroplast genomes with over $150 \times$ coverage. Two other reference genomes, Galium aparine (NC036969) and Galium mollugo (NC036970), were also downloaded for gene annotation using the Geseq platform. Annotated genes were manually verified and adjusted. The circular plastid genome maps were then drawn using OrganellarGenomeDRAW [38] (Figure 1). The three annotated chloroplast genomes were deposited in GenBank (https: / / www.ncbi.nlm.nih.gov) with corresponding accession numbers.

\subsection{Repeat Elements Analysis}

MISA PERL script [39] was used to detect the SSRs in the chloroplast genomes. For the SSR search parameters, the minimum number of repetitions of mono-, di-, tri-, tetra-, penta-, and hexa-nucleotides was 10, 5, 4, 3, 3 and 3, respectively. REPuter [40] was used to detect the size and location of repeats in the genome sequences. Four types of repeats: forward match, reverse match, complement match and palindromic match, were searched and analyzed. Parameters were set as three of hamming distance, 100 of maximum computed repeats and 30 of minimal repeat size.

\subsection{Sequence Divergence Analysis}

The chloroplast genomic sequences of the three species of Hedyotis were aligned by MAFFT [41]. DnaSP (DNA Sequences Polymorphism v6.12.03) [42] was used to analyze the nucleotide polymorphisms from the three aligned DNA sequences. The parameters for sliding window analysis were set as 600 sites of window length and 200 sites of step size. Nucleotide diversity ( $\mathrm{Pi}$ ) of each mid-point was computed for constructing a DNAsp graph indicating the sequence variation among the three species of Hedyotis (Figure 4). In-house python coding developed by Seoul National University was used to determine the number and position of indels and SNPs.

\subsection{Phylogenetic Analysis}

Phylogenetic analysis was conducted using the complete chloroplast genomic sequences of the three Hedyotis species in this study and 21 species of Rubiaceae available in NCBI, including Hedyotis ovata (MK203877), Leptodermis scabrida (MN686284), Paederia scandens (MN567112), Dunnia sinensis (MN883829), Rubia cordifolia (NC047470), Galium mollugo (NC036970), Galium aparine (NC036969), Saprosma merrillii (MK203879), Morinda officinalis (NC028009), Morinda citrifolia (NC047302), Coffea arabica (NC008535), Coffea canephora (NC030053), Gardenia jasminoides (CM023130), Scyphiphora hydrophyllacea (MN390972), Emmenopterys henryi (NC036300), Mussaenda hirsutula (MK203878), Antirhea chinensis (NC_044102), Mitragyna speciosa (NC034698), Uncaria rhynchophylla (MN723865), Neolamarckia cadamba (NC041149) and Neolamarckia macrophylla (MN877388). Gentiana officinalis (MH261261) was used as an outgroup. The complete chloroplast genomic sequences were aligned by MAFFT [41]. The best nucleotide substitution model (GTR + G +I) was tested. Mega-X software [43] was used to construct the maximum likelihood (ML) with 1000 bootstrap replicates. 


\subsection{Development of DNA Barcoding Markers}

The genomic sequences of the three Hedyotis species were first aligned by MAFFT. Primers were designed (Table S1) from the hotspot divergence regions concluded from the sequence divergence analysis session. The designed primers were subjected to OligoAnalyzer 3.1 (Integrated DNA Technologies, Inc., Coralville, IA, USA) for evaluation. Ten emphHedyotis samples were collected from herbal shops in Hong Kong. DNA was extracted and amplified by polymerase chain reaction (PCR). The PCR products were purified and sequenced by Sanger sequencing (BGI, Hong Kong, China). Sequenced amplicons were aligned with our chloroplast genomes by MAFFT.

\section{Conclusions}

In this study, the complete chloroplast genomes of $H$. diffusa, $H$. brachypoda and $H$. corymbosa were constructed and analyzed. The genome size ranged from 152,327 bp to $153,653 \mathrm{bp}$. Different comparative analyses showed that the genomic differences were derived from: (1) the number of protein-coding genes, (2) the presence of various pseudogenes, (3) the number and distribution of simple and dispersed repeats and (4) the distinct species-specific sequences. These findings enhanced our knowledge and understanding of the chloroplast genomes and the phylogenetic relationship of the four Hedyotis species and other species of Rubiaceae. The phylogenetic tree indicated that the four species of Hedyotis were closely related. This study also developed DNA barcoding markers from $n d h D$ and rps16-trnQ for species authentication. Proper authentication of herbal material is of the utmost importance. The correct use of herbal ingredients in cooling beverages helps to enhance quality assurance and quality control in the herbal industry and safeguard the safety of consumers. We anticipate that the two unique DNA markers generated in this study can be used for quality control and authentication of $H$. diffusa in the herbal industry.

Supplementary Materials: The following are available online at https:/ / www.mdpi.com/2223-7747/ 10/1/161/s1, Table S1: Sequences and parameters of the designed primers. Table S2: The amplified sequences from the ten sample.

Author Contributions: Conceptualization, M.H.-Y.Y., B.L.-H.K. and P.-C.S.; investigation, T.-Y.S. and D.T.-W.L.; methodology, M.H.-Y.Y. and B.L.-H.K.; software, M.H.-Y.Y. and B.L.-H.K.; supervision, P.-C.S.; writing—original draft, M.H.-Y.Y. and B.L.-H.K.; writing—review and editing, T.Y.S., D.T.-W.L., H.C. and P.-C.S. All authors have read and agreed to the published version of the manuscript.

Funding: This research received no external funding.

Institutional Review Board Statement: Not applicable.

Informed Consent Statement: Not applicable.

Data Availability Statement: The chloroplast genomes presented in this study are openly available in GenBank with reference number MT767006-MT767008.

Conflicts of Interest: The authors declare no conflict of interest.

\section{References}

1. Yang, Y.-C.; Lu, F.-H.; Wu, J.-S.; Wu, C.-H.; Chang, C.-J. The Protective Effect of Habitual Tea Consumption on Hypertension. Arch. Intern. Med. 2004, 164, 1534-1540. [CrossRef]

2. Chen, T.; Taylor, C.M. Hedyotis. Flora China 2011, 19, 147-174.

3. Groeninckx, I.; Dessein, S.; Ochoterena, H.; Persson, C.; Motley, T.J.; Kårehed, J.; Bremer, B.; Huysmans, S.; Smets, E. Phylogeny of the Herbaceous Tribe Spermacoceae (Rubiaceae) Based on Plastid DNA Data1. Ann. Mo. Bot. Gard. 2009, 96, 109-132. [CrossRef]

4. Nimal Christhudas, I.V.; Praveen Kumar, P.; Sunil, C.; Vajravijayan, S.; Lakshmi Sundaram, R.; Jenifer Siril, S.; Agastian, P. In vitro studies on alpha-glucosidase inhibition, antioxidant and free radical scavenging activities of Hedyotis biflora L. Food Chem. 2013, 138, 1689-1695. [CrossRef] [PubMed]

5. Ahmad, R.; Ali, A.M.; Israf, D.A.; Ismail, N.H.; Shaari, K.; Lajis, N.H. Antioxidant, radical-scavenging, anti-inflammatory, cytotoxic and antibacterial activities of methanolic extracts of some Hedyotis species. Life Sci. 2005, 76, 1953-1964. [CrossRef] 
6. Ye, M.; Su, J.J.; Liu, S.T.; Cao, L.; Xiong, J.; Zhao, Y.; Fan, H.; Yang, G.X.; Xia, G.; Hu, J.F. (24S)-ergostane-3beta,5alpha,6beta-triol from Hedyotis chrysotricha with inhibitory activity on migration of SK-HEP-1 human hepatocarcinoma cells. Nat. Prod. Res. 2013, 27, 1136-1140. [CrossRef]

7. Shan, B.E.; Zhang, J.Y.; Du, X.N. Immunomodulatory activity and anti-tumor activity of Oldenlandia diffusa in vitro. Zhongguo Zhong xi yi jie he za zhi Zhongguo Zhongxiyi jiehe zazhi Chin. J. Integr. Tradit. West. Med. 2001, 21, 370-374.

8. Yan, Z.; Feng, J.; Peng, J.; Lai, Z.; Zhang, L.; Jin, Y.; Yang, H.; Chen, W.; Lin, J. Chloroform extract of Hedyotis diffusa Willd inhibits viability of human colorectal cancer cells via suppression of AKT and ERK signaling pathways. Oncol. Lett. 2017, 14, 7923-7930. [CrossRef]

9. Yue, G.G.-L.; Lee, J.K.-M.; Chan, B.C.-L.; Kwok, H.-F.; Hoi, S.W.-H.; Sze, D.M.-Y.; Fung, K.-P.; Leung, P.-C.; Lau, C.B.-S. An innovative anti-cancer Chinese herbal formula exhibited multi-targeted efficacies in metastatic breast cancer mouse model. Chin. Med. 2018, 13, 64. [CrossRef]

10. Li, Q.; Lai, Z.; Yan, Z.; Peng, J.; Jin, Y.; Wei, L.; Lin, J. Hedyotis diffusa Willd inhibits proliferation and induces apoptosis of 5FU resistant colorectal cancer cells by regulating the PI3K/AKT signaling pathway. Mol. Med. Rep. 2018, 17, 358-365.

11. Lau, C.B.S.; Cheng, L.; Cheng, B.W.H.; Yue, G.G.L.; Wong, E.C.W.; Lau, C.-P.; Leung, P.-C.; Fung, K.-P. Development of a simple chromato-graphic method for distinguishing between two easily confused species, Hedyotis diffusa and Hedyotis corymbosa. Nat. Prod. Res. 2012, 26, 1446-1450. [CrossRef] [PubMed]

12. Li, M.; Jiang, R.-W.; Hon, P.-M.; Cheng, L.; Li, L.-L.; Zhou, J.-R.; Shaw, P.-C.; But, P.P.-H. Authentication of the anti-tumor herb Baihuash-eshecao with bioactive marker compounds and molecular sequences. Food Chem. 2010, 119, 1239-1245. [CrossRef]

13. Song, Y.; Chen, Y.; Lv, J.; Xu, J.; Zhu, S.; Li, M. Comparative Chloroplast Genomes of Sorghum Species: Sequence Divergence and Phylogenetic Relationships. BioMed Res. Int. 2019, 2019, 5046958. [CrossRef] [PubMed]

14. Dong, W.; Xu, C.; Wu, P.; Cheng, T.; Yu, J.; Zhou, S.-L.; Hong, D.-Y. Resolving the systematic positions of enigmatic taxa: Manipulating the chloroplast genome data of Saxifragales. Mol. Phylogenetics Evol. 2018, 126, 321-330. [CrossRef]

15. Moore, M.J.; Bell, C.D.; Soltis, P.S.; Soltis, D.E. Using plastid genome-scale data to resolve enigmatic relationships among basal angi-osperms. Proc. Natl. Acad. Sci. USA 2007, 104, 19363-19368. [CrossRef] [PubMed]

16. Dong, W.; Liu, J.; Yu, J.; Wang, L.; Zhou, S. Highly Variable Chloroplast Markers for Evaluating Plant Phylogeny at Low Taxonomic Levels and for DNA Barcoding. PLoS ONE 2012, 7, e35071. [CrossRef] [PubMed]

17. Dong, W.; Xu, C.; Cheng, T.; Lin, K.; Zhou, S. Sequencing Angiosperm Plastid Genomes Made Easy: A Complete Set of Universal Primers and a Case Study on the Phylogeny of Saxifragales. Genome Biol. Evol. 2013, 5, 989-997. [CrossRef]

18. Raman, G.; Park, S. The Complete Chloroplast Genome Sequence of Ampelopsis: Gene Organization, Comparative Analysis, and Phylogenetic Relationships to Other Angiosperms. Front. Plant Sci. 2016, 7. [CrossRef]

19. Zhou, T.; Wang, J.; Jia, Y.; Li, W.; Xu, F.; Wang, X. Comparative Chloroplast Genome Analyses of Species in Gentiana section Cruciata (Gentianaceae) and the Development of Authentication Markers. Int. J. Mol. Sci. 2018, 19, 1962. [CrossRef]

20. Yu, X.; Zuo, L.; Lu, D.; Lu, B.; Yang, M.; Wang, J. Comparative analysis of chloroplast genomes of five Robinia species: Genome comparative and evolution analysis. Gene 2019, 689, 141-151. [CrossRef]

21. Lu, R.-S.; Li, P.; Qiu, Y. The Complete Chloroplast Genomes of Three Cardiocrinum (Liliaceae) Species: Comparative Genomic and Phylogenetic Analyses. Front. Plant Sci. 2017, 7, 2054. [CrossRef] [PubMed]

22. Maier, R.M.; Neckermann, K.; Igloi, G.L.; Kössel, H. Complete Sequence of the Maize Chloroplast Genome: Gene Content, Hotspots of Divergence and Fine Tuning of Genetic Information by Transcript Editing. J. Mol. Biol. 1995, 251, 614-628. [CrossRef] [PubMed]

23. Hupfer, H.; Swiatek, M.; Hornung, S.; Herrmann, R.G.; Maier, R.M.; Chiu, W.-L.; Sears, B. Complete nucleotide sequence of the Oenothera elata plastid chromosome, representing plastome I of the five distinguishable Euoenothera plastomes. Mol. Genet. Genom. 2000, 263, 581-585. [CrossRef] [PubMed]

24. Menezes, A.P.A.; Resende-Moreira, L.C.; Buzatti, R.S.O.; Nazareno, A.G.; Carlsen, M.; Lobo, F.P.; Kalapothakis, E.; Lovato, M.B. Chloroplast genomes of Byrsonima species (Malpighiaceae): Comparative analysis and screening of high divergence sequences. Sci. Rep. 2018, 8, 1-12. [CrossRef] [PubMed]

25. Raman, G.; Park, S. Analysis of the Complete Chloroplast Genome of a Medicinal Plant, Dianthus superbus var. longicalyncinus, from a Comparative Genomics Perspective. PLoS ONE 2015, 10, e0141329. [CrossRef] [PubMed]

26. Gray, M.W.; Covello, P.S. RNA editing in plant mitochondria and chloroplasts. FASEB J. 1993, 7, 64-71. [CrossRef]

27. Weng, M.L.; Blazier, J.C.; Govindu, M.; Jansen, R.K. Reconstruction of the ancestral plastid genome in Geraniaceae reveals a corre-lation between genome rearrangements, repeats, and nucleotide substitution rates. Mol. Biol. Evol. 2014, 31, 645-659. [CrossRef]

28. Xu, C.; Dong, W.; Li, W.; Lu, Y.; Xie, X.; Jin, X.; Shi, J.; He, K.; Suo, Z. Comparative Analysis of Six Lagerstroemia Complete Chloroplast Genomes. Front. Plant Sci. 2017, 8, 15. [CrossRef]

29. Nazareno, A.G.; Carlsen, M.; Lohmann, L.G. Complete Chloroplast Genome of Tanaecium tetragonolobum: The First Bignoniaceae Plastome. PLoS ONE 2015, 10, e0129930. [CrossRef]

30. Zhang, Y.; Du, L.; Liu, A.; Chen, J.; Wu, L.; Hu, W.; Zhang, W.; Kim, K.; Lee, S.C.; Yang, T.J.; et al. The Complete Chloroplast Genome Se-quences of Five Epimedium Species: Lights into Phylogenetic and Taxonomic Analyses. Front Plant Sci. 2016, 7, 306.

31. Khakhlova, O.; Bock, R. Elimination of deleterious mutations in plastid genomes by gene conversion. Plant J. 2006, 46, 85-94. [CrossRef] [PubMed] 
32. Li, X.; Yang, Y.; Henry, R.J.; Rossetto, M.; Wang, Y.; Chen, S. Plant DNA barcoding: From gene to genome. Biol. Rev. Camb. Philos. Soc. 2015, 90, 157-166. [CrossRef] [PubMed]

33. Yang, J.-B.; Tang, M.; Li, H.; Zhang, Z.; Li, D.Z. Complete chloroplast genome of the genus Cymbidium: Lights into the species identification, phylogenetic implications and population genetic analyses. BMC Evol. Biol. 2013, 13, 84. [CrossRef] [PubMed]

34. Hollingsworth, P.; Graham, S.W.; Little, D.P. Choosing and Using a Plant DNA Barcode. PLoS ONE 2011, 6, e19254. [CrossRef]

35. But, G.W.-C.; Wu, H.-Y.; Shaw, P.C. Identification of fish species of sushi products in Hong Kong. Food Control 2019, 98, 164-173. [CrossRef]

36. Lo, Y.-T.; Li, M.; Shaw, P.C. Identification of constituent herbs in ginseng decoctions by DNA markers. Chin. Med. 2015, 10, 1-8. [CrossRef]

37. Sivarajan, V.V.; Biju, S.D. Taxonomic and nomenclatural notes on the Hedyotis corymbosa-diffusa complex (Rubiaceae) in India. Taxonomy 1990, 39, 665-674. [CrossRef]

38. Lohse, M.; Drechsel, O.; Kahlau, S.; Bock, R. OrganellarGenomeDRAW—a suite of tools for generating physical maps of plastid and mitochondrial genomes and visualizing expression data sets. Nucleic Acids Res. 2013, 41, W575-W581. [CrossRef]

39. Beier, S.; Thiel, T.; Münch, T.; Scholz, U.; Mascher, M. MISA-web: A web server for microsatellite prediction. Bioinformatics 2017, 33, 2583-2585. [CrossRef]

40. Kurtz, S.; Choudhuri, J.V.; Ohlebusch, E.; Schleiermacher, C.; Stoye, J.; Giegerich, R. REPuter: The manifold applications of repeat analysis on a genomic scale. Nucleic Acids Res. 2001, 29, 4633-4642. [CrossRef]

41. Katoh, K.; Standley, D.M. MAFFT Multiple Sequence Alignment Software Version 7: Improvements in Performance and Usability. Mol. Biol. Evol. 2013, 30, 772-780. [CrossRef] [PubMed]

42. Rozas, J.; Ferrer-Mata, A.; Sánchez-DelBarrio, J.C.; Guirao-Rico, S.; Librado, P.; Ramos-Onsins, S.E.; Sánchez-Gracia, A. DnaSP 6 : DNA Sequence Polymorphism Analysis of Large Data Sets. Mol. Biol. Evol. 2017, 34, 3299-3302. [CrossRef] [PubMed]

43. Kumar, S.; Stecher, G.; Li, M.; Knyaz, C.; Tamura, K. MEGA X: Molecular Evolutionary Genetics Analysis across Computing Plat-forms. Mol. Biol. Evol. 2018, 35, 1547-1549. [CrossRef] [PubMed] 